\title{
CROSS-CULTURAL REALITIES IN THE JOURNALISTIC DISCOURSE AND THEIR SIGNIFICANCE IN FOREIGN LANGUAGE LEARNING
}

\author{
Nataliia Glinka \\ National Technical University of Ukraine "Igor Sikorsky Kyiv Polytechnic Institute”, Kyiv, Ukraine \\ nvglinka@ukr.net
}

\author{
Galyna Usyk \\ National Technical University of Ukraine “Igor Sikorsky Kyiv Polytechnic Institute”, Kyiv, Ukraine \\ galinausik@gmail.com
}

\author{
Yuliya Ilchuk \\ Stanford University, Palo Alto, USA \\ yilchuk@stanford.edu
}

\begin{abstract}
The paper examines the journalistic discourse as a linguistic phenomenon in the socio-cultural realities. The relevance of the study is determined by the great interest of linguistic science to the issues of cross-cultural communication and their significance in teaching English as a foreign language. The journalistic discourse is a peculiar phenomenon of linguistics because it reflects socio-cultural features of specific communication space; it creates a language picture of the world of a certain culture and society through the specific socio-cultural lexical units - realities. The main aim of the study is to examine, analyse, summarise and systematise sociocultural linguistic resources as a means of creating and transmitting linguistic awareness, revealing the pragmatic aspects of their functioning in the journalistic discourse. In order to achieve this goal the following steps have been taken: 1) to study the characteristics of the journalistic discourse; 2) to determine the specific genres of the journalistic discourse of the English language periodicals and mass media on-line resources; 3 ) to investigate the cognitive and pragmatic features of the vocabulary functioning, which reflect the peculiarities of the English language context of the socio-cultural aspect of the journalistic discourse; 4) to categorise and analyse the thematic and typological groups of socio-cultural realities and study their functions in the context. The possible application of the obtained results is to develop the scientific and teaching facilities in the field of foreign language learning and translation.
\end{abstract}

Keywords: journalistic discourse; functions; categories of realities; cognitive and pragmatic analysis.

\section{Introduction}

Journalistic discourse is a communicative and linguistic phenomenon which forms the idea of the language picture of the world. The scholarly novelty of this study lies in treating journalistic discourse as a socio-cultural linguistic phenomenon of modern communication space. We approach this phenomenon thorough study of socio-cultural vocabulary in terms of modern cognitive science, pragmatic and translation. The purpose of the study is to examine and systematise socio-cultural linguistic resources as a means of creating the linguistic picture of the world and revealing the pragmatic aspects of their functioning in the journalistic discourse. In order to achieve this goal we tried to solve the following problems: 1) to study the characteristics of journalistic discourse; 2) to determine the specifics of journalistic discourse of Englishlanguage periodicals and mass media online resources; 3 ) to investigate the cognitive and pragmatic features of the functioning of vocabulary which reflect the peculiarities of the English-speaking context of sociocultural journalistic discourse; 4) to analyse and characterise socio-cultural units of journalistic discourse according to their thematic and typological groups.

To achieve the goals, the following research methods were used: the method of conceptual, distribution and quantitative analysis; the method of observation, systematisation and generalisation of the research material; the method of continuous sampling; the method of critical analysis and the method of context analysis.

The proper understanding of the journalistic discourse is impossible without a comprehensive overview of the notion of discourse. This notion lies at the basis of the research of most linguists such as Halliday (1978), Van Dijk (1992; 2006), Arutjunova (1990), Karasyk (2009), Batzevich (2015), Beljaiivska (2000), Volf (2002), Kosjuk (2012), etc.

The material of our analysis of the journalistic discourse elements was based on the most popular mass media sources in Ukraine (Kyiv Post, The Day), the UK (The Guardian, BBC.com, Home of Daily and Sunday Express, Newsweek), and the USA (Voice of America, USATODAY). From each of the abovementioned media outlets, several publications were used to extract the lexical units indicating culture-bound items (realities): geographic, ethnographic and socio-political terms. The focus of our study was on the 
socio-cultural events in different contexts. For this reason, we have chosen a variety of the subject matter: from politics to culinary. The number of such lexical units reached 1000 words.

The theoretical value of the study lies in the following: its results contribute to the further study of the structural semantics, cognitive linguistics and pragmatics, knowledge of the fragments of the worldview, and its application in the translation studies.

The practical significance of the results is that the material collected can be further used as teaching facilities in the field of foreign language learning and translation.

\section{General notion of discourse in modern linguistics}

One of the characteristic features of the discourse is its focus on a recipient. The term "discourse" is very popular and has become a part of the linguistic mainstream though so far it has not acquired the uniformed definition. Arutjunova (1990) designates discourse as a coherent text in conjunction with extralinguistic, socio-cultural, pragmatic, psycho-linguistic and other factors which are taken as "speech submerged in life" (p.136-137). It is further regarded as a complex communicative phenomenon which embraces the social context, information about communicators, knowledge of the process of production, and perception of the text. Discourse can denote language activities, text and context, and expression in its interconnection with communicative situation. It is believed that there is no point in using the term discourse to denote those ideas which have already had their fixed names. For example, there is hardly any sense in calling a context (a fragment of a text), a text or a communicative act as discourse. Usually, it is treated as a much wider notion.

According to Van Dijk (1990), discourse is not restricted to the frames of a text but it also includes the social context of communication which characterises the participants, the processes of production and perception of language with regard to their background knowledge (p. 11-14). This means that discourse includes not only a text but such extra-linguistic notions as knowledge about the world, mental outlook, and attitude.

Linguistic encyclopedia by Ganich \& Olijnyk (1985) gives the following definition to discourse (from French "discours" - language): it is a coherent text together with extra-linguistic, pragmatic, socio-cultural, psychological and other factors; a text taken in the aspect of action and life; language that is considered as an object-oriented act, as a component which takes part in peoples' interaction and in the mechanisms of their consciousness (p.75).

\section{Journalistic discourse}

In our treatment of discourse, we consider the central ideas expressed by linguists: discourse is aimed at a recipient within the communicative act. We consider the following main genres of journalism are a chapter, journalistic story, analytical review, commentary, etc.

3.1 Genres of journalistic discourse. Arutjunova (1990) argues that genre is a specific dynamic model of structural and language organisation of some communication texts composed by extra-linguistic factors of communication (p. 48). According to Ericson (2005), a genre is a communication pattern which is created under the influence of individual, social, and technological factors which are tangentially present in the reconstructed communication situation. The genre, as a steady model of communication act, occurs in a concrete sphere of communication and depends on the factors of communicative situation. By British linguist Swales (1990), a genre is a mediator between an individual and a society; he sees the connection of the genre with the discourse practice in the society and notices the dependence of structure and content on predetermined and set targets and social mechanisms that regulate it.

The subject of journalism is the societal reality, public and political aspects of human lives, economic, moral, artistic, scientific and spiritual issues.

Los (2008), Ukrainian academic specialist in the sphere of journalism and language influence on the society, argues that the following definition for journalism is fair: journalism is a social science and human study (p. 25). Society and humans are two sides of one and the same subject of journalism which have deep and tight connections. Journalism addresses and in all scientific depth researches the functioning of a person as a social member within a social medium.

Journalism is the major source and the most active distribution channel of neologisms: lexical, wordforming, and phraseological.

Journalistic discourse is a specific type of communicative phenomenon with its task aimed at society. Diverse approaches to information delivery result in different kinds of influence on the recipient that is why it seems reasonable to emphasise the peculiarity of a journalistic discourse. Journalistic discourse is often called the "language of media" or "discourse of mass media" (Bell, 1995). 
3.2Functions of journalistic discourse. The specific structure of journalistic discourse has its centre and periphery: opinion chapter, commentary, editorial, running commentary, news story, pamphlet, and feuilleton form the core genres of the journalistic discourse while interview, polemics, a political document, and statute reside on the periphery (Bell, 1995). These elements of the journalistic discourse perform the following functions: to control crowd behaviour and to manipulate their consciousness by using the method of distortion of facts and of information fabrication among others; to be an instrument of propaganda (to spread political, philosophic, scientific, cultural, and other ideas throughout a society in order to shape specific views within great masses of the population); to provide the focus for the social political environment and to conceptualise reality; to form new ideology (the system of political, legal, religious, aesthetic, and philosophic ideas inside which people's attitudes to reality are perceived and estimated); to be a tool of socialisation (transferring the cultural heritage from one generation to the other) (Zheltukhina, 2003).

Journalistic discourse can aid in the social estimation - that is to introduce positive or negative judgment of certain facts, individuals or events in a society; the journalistic discourse also has a great communication value and special feature of expressiveness.

The evaluative factor is created with the help of clichés, combinations of certain words and their semantics which form a fixed pattern of information perception and, to some extent, an automatic response. Those lexical units that reproduce the conditions which are close to recipients play a special role.

Summing up various approaches to the journalistic discourse, we should emphasise on a specific structural-functional variety of the standard language which is a particular component of a cultural-historic paradigm of a society because it comprises a great deal of lexical-stylistic elements. For more detailed analysis of the journalistic discourse elements, we propose to study such forms of it as English newspapers and on-line periodicals in Ukraine, the USA and Great Britain.

3.3 Specific lexical features of the journalistic discourse. The journalistic discourse comprises a number of specific lexical units which denote such phenomena or concepts that are characteristic of a certain nation and their linguistic view of the world. Most of these units are classified as culture-specific vocabulary or linguistic realities. As far as this linguistic phenomenon is concerned, scholars' ideas on the point are many and various. The culture-specific vocabulary which forms a background knowledge presents a great interest in the analysis of the interaction between language and culture.

The most thorough research in the sphere of culture-specific vocabulary was done by Bulgarian linguists Vlakhov \& Florin (2009) who, in their book "Untranslatable in Translation", give the following definition of the idea of this lexis: they are words or word-collocations which denote objects characteristic of life (household activities, culture, social and historical development) of one nation and foreign to the other; in this way, these words, being the carriers of national and/or historical colour, do not have adequate equivalents in other languages and special approaches should be used for their translation.

According to Akhmanova (2004), culture-specific vocabulary is the subject of the material culture of a nation, which is historically formed on the economy basis.

The culture-specific vocabulary can refer to objects, notions and peculiarities of a certain geographical place, and depict a local colour (Alekseeva, 2001, p. 145). It can be classified into different categories. According to Vlakhov \& Florin (2009), there can be the following divisions: subject classification, chronological classification, and location classification. By the subject classification the culture-specific words can be grouped as following: geographic realities: names of physical geography objects (steppe, passat); objects related to human activity (dacha, rancho); names of endemics (sequoia, iguana); ethnographic realities (objects of culture and everyday life): clothes (sarafan, kimono, plakhta); labour (cowboy, concierge, brigadier); elements of arts and culture (harlequin, balalaika, hopak); ethnic elements (hutzul, chukcha, basks); money (pound, hryvna, yenna); social-political realities: administrative division (oblast, county, canton), bodies of power (Rada, White House, Duma, viche); military men (Cossack, ataman), organisations, ranks, titles, status, caste (prince, vice-premier, knyazh); transport: roads and vehicles (federal highways, levitation train); workforce (HR - human resource, blogger - a journalist who writes for a web page that is made up of information about a particular subject,); political life (vote of noconfidence, inauguration, impeachment); public holidays (bank holiday - an official holiday when banks and most businesses are closed, Day of German Unity; Independence Day); ethnonyms (Dutch, Friesians).

Chronological classification studies the same linguistic units only from a different angle. They are divided into two big groups: contemporary realities (social media addiction, PR-manager) and historical realities, peculiar to notions of the past (khrushchovka, komunalka, slavery). 
By location classification, within one and the same language, the realities can be defined as one's own realities (from a given language) and as foreign realities (borrowings assimilated in the given language as a literal translation, or transliteration, or calque).

To our mind, classification of language realities suggested by Konetzka (1978), is quite relevant because it narrows the boundaries of linguistic realities field and by this reason we will use it in our research (pp.463-466). The linguist restricts her classification to socio-political life of a community and distinguishes the following categories of linguistic realities:

1. Socio-political institutions and organisations: Federal Employment Fund, KGB, CIA;

2. Processes and events of social and human importance: Teaching staff shortage, Orange Revolution, Maidan;

3. Names of administrative division: State, District, Krai;

4. Different agencies, residences of public figures, buildings: the White House, The Buckingham's Palace;

5. Professional, gender, national and religious groups: The State Fishing Committee, Pope of Rome, Basque separatists;

6. Habits, traditions, celebrations, games: hide-and-seek, kulich, koliadky, five o'clock tea;

7. Units of measurement, currency units: inch, gallon, hryvna;

8. Names of businesses: Microsoft, Apple, Kievenergo.

Tomakhin (1988), who studies the realities, divides them into three large groups:

1. Onomastic realities - geographic names (toponyms) especially those which have cultural and historical associations, e.g. Ivano-Frankivsk, Rome;

2. Appellation lexis - anthroponomy (historical and public figures, scientists, writers, men of art, sportsmen, characters of fiction, and heroes of folklore) e.g. Snegurochka, Cinderella, Churchill);

3. Aphoristic realities - titles of pieces of literature and art, historical facts and events of a country, names of state institutions and social organisations, e.g. The Warlord, Crime and Punishment, International Money Fund.

Similar to any other classification of linguistic units which do not easily yield to clear-cut categorisation, such division of realities is to a great extent reductive and lays claim neither to the absolute fullness of details nor to ultimate attachment of certain units to the correspondent category.

Thereby, having studied different points of view on the classification of culture-specific words, we can come to the conclusion that they are mostly grouped by thematic principles.

\section{Quantitative analysis of social-cultural elements of the English journalistic discourse}

Our analysis of the journalistic discourse elements was based on the most popular mass media sources of Ukraine (KyivPost, The Day), the UK (The Guardian, BBC.com, Home of Daily and Sunday Express, Newsweek), and the USA (Voice of America, USATODAY). From each of above-mentioned editions, 20 publications were used to extract the lexical units indicating culture-bound items (realities): geographic, ethnographic and socio-political terms. The focus of our study was on the socio-cultural events in different contexts. For this reason, we have chosen from a variety of subject matter: from politics to culinary.

4.1 Socio-cultural units in the newspaper discourse. The quantitative analysis showed the extensive examples of socio-cultural units in the English language discourse of different countries; as for the percentage rate, it showed approximately equal readings: American editions - 30\%, British editions $-25 \%$, and Ukrainian editions $-45 \%$. Despite these insignificant discrepancies in number, they all have a common thread: they carry the sense of socio-cultural environment and emotional colouring of the information given.

For example, in the English language Ukrainian newspaper The Day, we find the following: The picture is usual, but after the events of 2013-14 and after the political leaders of the Revolution of Dignity came to power, these slogans were wounding the ear, mildly speaking. This passage contains the name of an event which has played a prominent role in lives of all Ukrainians, namely the revolution which happened in the winter of 2013-2014 and made it possible for the citizens of Ukraine to feel their own honour and dignity. This particular feeling gave the name to the event. So far we cannot find this term in the history textbooks, this is why for the foreigners who lacked the interest in Ukrainian political life during the revolution and Maidan the contextual meaning of the collocation the Revolution of Dignity can be less expressive than for the participants and witnesses of these events.

Investigating the British editions Express, Home of the Daily and Sunday Express, in chapters "Dell support paves the way for tech start-ups' growth" and "Boris Johnson caught up in mid-air drama after attempting to calm 'off his head' passenger" we have found the following realities: proper names, socio- 
political realities and metaphors-neologisms. E.g. Being at the heart of Dell has certainly broadened our perspective (an American privately owned multinational computer technology company founded by Michael Dell). Poised to launch pilots of its first cloud-based product early next year, Fantoo, which employs 10, expects a $£ 600,000$ turnover by the end of next year (metaphor-neologism describing new computing technology). Customers already include public bodies such as the Metropolitan Police (proper name the police force for Greater London), as well as Mark \& Spencer and telephone giants EE (abbreviation a British mobile phone network) and Telephonica (proper name - a European broadband and telecommunications company). Boris Johnson was at the centre of a mid-air drama as he attempted to calm an "off his head" fellow passenger during a long-haul flight (proper name: The Mayor of London).

In the American edition USATODAY, we have analysed a chapter "First Take: Watch Wage Growth, Not Job Gain" which includes some examples of socio-political realities. E.g. Wall Street (a street in New York City which runs through the historical centre of the Financial District) concentrated on the number of jobs created in 2014. In 2015, investors should keep a close eye on wages. Whether the Federal Reserve System (the central banking system of the United States) can do that in time is an open question.

One more abstract from the other American edition demonstrates the examples of socio-political institutions, ranks and geographic names. E.g. The chain of acts of civil disobedience culminated in RCDGoma's (Rally for Congolese Democracy-Goma) refusal to allow Archbishop (a Christian bishop of higher rank or office) Kataliko to return to his parish in Bukavu (a city in the Eastern Democratic Republic of the Congo).

The following examples contain the ethnographic realities: E.g. It is a month of feasting that may begin with wan canapés (a small, prepared and usually decorative food, held in the fingers and often eaten in one bite from a Chinese restaurant, the name comes from the French word for "couch or sofa") at the office holiday party but ends with long, joyful run into New Year's Eve with its promise of morning hoppin' john (peas and rice dish served in the southern states of the United States on New Year's Day which is thought to bring a prosperous year filled with luck) and a glass of Champagne (sparkling wine of French origin). A man named John Chapman, who later became known in American folklore Johnny Appleseed, helped accelerate the spread of apples across America by planting extensive orchards (Johnny Appleseed is a legendary name of a real person who became a popular figure in the American folklore because of his perseverance in planting apple trees).

Summing up this section, we can state that every chapter from different editions contains a great number of socio-cultural units which contribute to the formation of a deeper insight into the socio-cultural lives of different nations among readers. The diversity of realities in journalistic discourse exercises emotional and expressive influence on the readers.

4.2 Analysis of socio-cultural units from different newspaper sections. In our further analysis, we investigate the usage of socio-cultural units in the chapters from different topic sections of the English language newspapers. Such sections as "Culture", "Politics", "Health and Sports", "Travel" were chosen to analyse the socio-cultural phenomena of journalistic discourse.

4.2.1 Culture. In mass media and in the Internet information sources, the section "Culture" covers a wide scope of domains: theatre and photography, TV and films, dances and opera, etc. Culture is believed to mediate the whole system of material and spiritual values of a society. The notion 'culture' embodies science and technology, education and art, morals and world view.

In the course of the analysis of 20 different editions of the topic "Culture", we spotted 217 socio-cultural units most of which were ethnographic realities (144), geographic realities (37) and socio-political realities (36). E.g. For others, it honors the appearance of the Virgin of Guadalupe (ethnographic reality) in Mexico (geographic reality) in 1531, or the birth of the Persian god of the sun (ethnographic reality), or the martyrdom of St. Lucia (ethnographic reality) or the miracle of couples from different cultures coming together to create their own. Ms. Saunders, a descendant of the Cherokee Nation (ethnographic reality), won the part and is thus starting her professional career on a live network extravaganza before an audience of millions, sharing the stage with the likes of Christopher Walken (as Captain Hook). Pantsula (a highly energetic dance form that originated in the black townships of South Africa during the Apartheid era ethnographic reality) isn't just a dance, but a way of life in Johannesburg's townships (geographic reality). With precise and technical footwork, often to the accompaniment of house music, pantsula dancers use hectic city streets as their stage surrounded by traffic, pedestrians and vendors. Beyond the totem poles (ethnographic reality) long displayed in the park, visitors to Vancouver (geographic reality) can now gain a fuller appreciation for the area's native people, known as First Nations (aboriginal Canadians - socio- 
political reality), by staying in the city's only First Nations' lodge, touring an expanded collection of native art, dining on First Nations cuisine and exploring the urban rain forest with a native guide.

While studying the chapters in the section "Culture" devoted to traditional national festivities, we find a lot of ethnographic realities which indicate the names of dishes, holidays or ethnic groups. Moreover, the realities in the English language journalistic discourse most realities are extraneous that is foreign to the English world culture, e.g. yassa turkey (a spicy marinated food prepared with onions and either poultry or fish coming from Senegal), jollof-dirty-rice (a one-pot rice dish popular in many West African countries), okonomiyaki (a Japanese savory pancake containing a variety of ingredients), varenik (are filled dumplings of Ukrainian origin). Socio-political category of realities is presented with the names of different institutions and geographic names. E.g. "It's just one of those symbols that captures what American life is," said Chef Gary Welling, an instructor at the International Baking and Pastry Institute at Jonson \& Wales University in Providence, Rhode Island.

Section "Culture" includes chapters on musical and theatre issues, entertainment and art as well as scientific issues because science is the part of human culture. The reality units here denote different musical and scientific instruments, specific terminology, also the names of cultural institutions, and certain organisations. E.g. There are five Grammy Awards (Gramophone Award, or Grammy, is an accolade by the National Academy of Recording Arts and Sciences of the United States) in the category of jazz (a music genre that originated from African-American communities of New Orleans in the United States). A Grammyish solo (a piece or a section of a piece played or sung by a single performer), by and large, is a framed event, a bravura (a style of both music and its performance intended to show off the skill of a performer) spot-lit performance, a physical display, an act of heroism.

Concluding the above-mentioned analysis of the "Culture" section we can state that the main function of journalistic discourse in this sphere is to transfer cultural message to the vast majority of people and broaden the readers' mind, which, in its turn, promotes high spiritual values and tolerance. Mostly used lexical units are the names of ethnographic realities, socio-cultural organisations, and geographic names.

4.2.2 Politics. Socio-cultural aspect of the journalistic discourse is closely tied to the social life of a certain nation and its political agenda. Chapters and blogs on political issues occupy a particular niche in the journalistic discourse. Such information is usually placed on the first page and concerns the situation in the world, growing social discontent over the politicians' activity and political processes in the country.

Politics represent everlasting topical and a dynamical fragment of reality in the linguistic view of the world, which influences all spheres of people's life. Such information makes it possible for readers to discover and learn more about other countries and to create international ties. Needless to say that power struggle is a driving force of all socio-political processes. Section "Politics" which focuses on power and civil servants, reforms and socio-political climate, is thought to be the most controversial and elusive in the journalistic discourse as its elements can be found in many other sections and rubrics.

Without a doubt, the section "Politics" embraces the biggest number of socio-political realities which denote administrative and territorial arrangement; names of power holders and government authorities; military agencies. E.g. With constitutional change looming and UKIP (the UK Independence Party (UKIP) is a Eurosceptic and right-wing populist political party in the United Kingdom) on the rise, England's identity (socio-political reality) and future has become a crucial, even disturbing political issue. An equally explosive question is whether England (toponymical reality) will receive a national voice, or be fragmented into regions for the first time since the reign of Edward the Confessor (nickname of one of the Anglo-Saxon kings of England).The religious and political conflicts of the 16th and 17th centuries, culminating in the civil war (warfare) and the glorious revolution, founded our modern political culture centred on Whig and Tory (political parties in the parliaments of England, Scotland, Great Britain and the United Kingdom) and their successors. The Ministry of Defense (government authority) estimates that acquiring four new submarines to carry the Trident (a submarine-launched ballistic missile) deterrent would cost $£ 31$ bn over the course of the 20-year procurement programme, with a further $£ 10 \mathrm{bn}$ set aside to meet any additional unexpected cost increases. Medical patients in the Evergreen State (toponymical nickname of the state of Washington) have been at the whims of overzealous U.S. attorneys or members of the Drug Enforcement Agency (the United States' federal law enforcement agency), who had discretion to ignore the Obama Administration's (a governmental body) admonition to let the local experiments play out.

To sum up, the analysis of this group of realities, we make sure that the greatest number of all chosen reality examples (367) was of ethnographic character (191), next group was of socio-political nature (102), and the least analysed group was of geographic realities (74). This supports the idea that the function of the journalistic discourse is to conceptualise the reality of political and social environment of the country; it 
creates the model of political reference and political reality. The whole complex of the socio-political realities becomes the basis for so-called sociodialect.

4.2.3 Sports and health. Observing the socio-cultural phenomenon of the journalistic discourse in the communication sphere, we can argue that indispensable part of a social well-being is health and people's attitude to the improvement of life quality. Sports play a very important role in achieving better physical shape.

The section "Sports and Health" includes chapters devoted to healthy lifestyle and sport, fitness and diet, and doctor's advice columns. We have also studied information on sports events and achievements as they demonstrate that sport is instrumental in developing of a certain culture. For our examination, we have selected 20 chapters from English-language newspapers, in which we have discovered an insufficient number of socio-cultural realities. Only 81 units were spotted in our material. Most chapters contained lexis of neutral semantics and a small part of those analysed included the following reality groups: names of institutions and agencies, ranks and titles, geographic names, and names of certain magazines and other editions. E.g. Luke Griggs (proper name), spokesperson for Headway UK (Headway Devon is a local charity in Devon, UK, which provides care, support, and rehabilitation for adults and children with brain injuries), the brain injury association, said: "Brain injury is often known as the hidden disability as often there are no obvious physical signs. At a Society of Neuroscience (professional group) meeting in Washington (geographic name) this month, a group of German (nationality) neurologists described the case of a professional cellist (profession), referred to as PM, who contracted herpes encephalitis in 2005. Chelsea (name of a football team) boss Guus Hiddink (proper name) believes his side have a "50-50" chance of reaching the Champions League (an annual European competition for football clubs) quarter-finals after Paris St-Germain (name of a football team) beat them 2-1 in the first leg of their last-16 tie. Responding to the findings, Barbara Dinsdale (proper name), lifestyle manager (occupation) for the charity Heart Research UK (charity organisation), said: "How many more wake-up calls do we need?"

These examples prove that the realities of this category of the journalistic discourse also belong to the socio-political (organisations and institutions), ethnographic (ranks and occupations, anthroponomy) and geographic (toponymical name) groups.

4.2.4 Travelling. One of the most important aspects of a human's life is travelling because of this activity people develop their personal culture. An individual, travelling themselves or reading accounts of other people's adventures, study different cultures, gains knowledge and experience, and broadens his/her mind. In this regard, the section "Travel" presents a specific interest in studying journalistic discourse and its content. From the analysed 20 chapters of English-language newspapers, we extracted 211 lexical units which denote socio-cultural peculiarities.

The journalistic discourse of the section "Travel" is rich in realities as there is a lot of particular information about countries and historical places. We have identified a lot of ethnographic realities which denote anthroponomical units, everyday objects, ethnic ideas, and names of ethnical groups. Socio-political realities were represented by names of authorities and power bodies, titles, ranks, castes, and also military realities. It is worth mentioning that these realities are mostly of a borrowed origin.

All these realities have a pragmatic function and help develop the recipients' cross-cultural competence. E.g. Our final day was spent in Lucknow (toponymical name - the capital city of the state of Uttar Pradesh, India), where a strong presence of the army and air force has helped preserve the cantonment area (permanent military stations) of large bungalows (a type of building) in generous and well-kept grounds. Admirably, the most famous memorial to the Indian Mutiny/First War of Independence (historical event Indian Rebellion of 1857) has been well cared for post-independence; the Residency (the usual name of the official residence of a Resident Commissioner appointed by the British crown) was besieged for 87 days, and fewer than a thousand of the original 2,994 incarcerated troops, sepoys (Indian soldiers) and civilians survived. Saris (a South Asian female garment) and kurta pajamas (an upper garment for men and women, originating in South Asia) were given to all passengers to wear at the final dinner, hosted by the Raja of Jehangirabad (a monarch or princely ruler in South and Southeast Asia) and his wife at their city palace in Lucknow (historical place). At the Chilean border (geographic place) we were met by the tour company, who drove us back to the camp, where a welcome asado (a range of barbecue techniques and the social event in Argentina, Chile, Paraguay and Uruguay, where it is an exceptionally popular dish) was waiting. Jeanne (anthroponomics) loves her food and I shop to my (and pocket's) content-sampling the finest macaroons (a type of small circular cake), truffles (food - the fruiting body of a subterranean Ascomycete fungus), and teas, stumbling upon hidden boutiques (dress shop) and ogling into the windows of Paris's leading fashionelite. 
These and other examples make it possible to conclude that socio-cultural units in the texts on "Travel" are quite frequent, most of which are ethnographic and geographic: 148 and 53 respectively. This quantitative result, in its turn, can be explained by the pragmatic orientation of this kind of discourse.

\section{Conclusions}

To conclude, the issue of the journalistic discourse has a great relevance in the modern linguistics as a lingo-cultural phenomenon of the modern communicative field. Analysing the functions of different genres in the journalistic paradigm, we can argue that the main functions of the journalistic discourse are informative and persuasive.

Our analysis of the journalistic discourse elements was based on such media sources as KyivPost, The Day, The Guardian, BBC.com, Home of Daily and Sunday Express, Newsweek, and Voice of America, USATODAY. From these editions, 20 publications were used to extract the lexical units indicating culturebound items (realities): geographic, ethnographic and socio-political terms. The focus of our study was on the socio-cultural events in different contexts. In the course of our study we have carried the quantitative analysis which showed the following: the examples of socio-cultural units in the English language journalistic discourse of different countries are extensive; as for the percentage rate, it showed approximately equal readings: American editions $-30 \%$, British editions $-25 \%$, and Ukrainian editions $-45 \%$. Although the number of realities differs from edition to edition, the tendency is quite similar: they contribute to the creation of the socio-cultural environment and expressiveness of the information presented.

The examples extracted from different sources of the journalistic discourse prove the idea of journalism being the powerful means and tool of socialisation and of spreading the information about unique peculiarities of a certain social medium and culture. As for the vocabulary that is used in the journalistic discourse, it can be qualified as diverse and wide. For our study, we have focused on socio-cultural realities as a means of reflecting different aspects of human life: social, political, cultural, etc. The analysis of these realities showed that they have a great effect on social thinking providing knowledge and forming the public attitude of mind. Studying the realities as something unique and specific to one particular society we can draw to the conclusion that they are indispensable elements in cross-cultural communication.

The results of our study contribute to the general linguistics theory and the theory of interlingual communication. As for their practical application, they are instrumental in foreign language learning and translation. This topic is the subject of our future research as it contains a lot of different facets the study of which can help understand pictures of the linguistic world of other societies.

\section{References:}

Alekseeva, I. (2001). Professionalnyj trenning perevodchika [Professional training of a translator]. St.Petersburg, Russia: Sojuz. Arutjunova, N.D. (1990). Discourse.In Lingvisticheskii encyklopedicheskii slovar (pp. 48, 136-137). V.N.Yartseva (Ed.), Moscow, Russia: SE.

Bell, A. (1995). Language and the Media. Annual Review of Applied Linguistics, 15, 23-41. https://doi.org/10.1017/s0267190500002592 Ganich, D. \& Olijnyk, I. (1985). Slovnyk lingvistychnyh terminiv [Dictionary of linguistic terms]. Kyiv, Ukraine: Vyshcha Shkola. Van Dijk, T. A. (1990). Discourse \& Society: A New Journal for a New Research Focus. Discourse \& Society, 1(1), 5-16.

Erickson, T. (2005). Rhyme and Punishment: the Creation and Enforcement of Conventions in an On-Line-Participatory Limerick Genre. https://doi.org/10.1109/hicss.1999.772647

Konetzkaja, V. (1978). Leksiko-semanticheskije kharakterystiki jazykovyh realii. In Velikobritania: Lingvostranovedcheskij slovar (pp. 463-466). Moscow, Russia: Russkii yazyk.

Los, J. (2008). Publicystyka I tendencii rozvytku svitu [Publicism and the tendencies of world development]. Lviv, Ukraine: PAIS.

Tomakhin, G. (1982). Amerika cherez amerikanizmy [America through Americanisms]. Moscow, Russia: Vyshchaja Shkola.

Vlakhov, S. \& Florin, S. (2009). Neperevodimoje v perevode [Untranslatable in Translation]. Moscow, Russia: R.Valent.

Swales, J.M. (1990). Genre Analysis. English in Academic and Research Setting. Cambridge: Cambridge University Press. https://doi.org/10.1075/z.184.513swa

Zheltukhina, M. (2003). Tropologicheskaja suggestivnost mass-medialnogo discursa. O probleme vozdeistvija tropov v jazyke SMI [Tropological suggestiveness in mass-media discourse. On the problem of speech influence of tropes in the language of media]. Moscow, Russia: Institut Yazykoznanija RAN. 